Published in: Community Ecology 14: 77-88 (2013)

Running head: Spatial variation in macroinvertebrate traits

\title{
Habitat filtering determines spatial variation of macroinvertebrate community traits in northern headwater streams
}

Dénes Schmera $^{1,2, *}$, Tibor Erös ${ }^{2}$ and Jani Heino ${ }^{3,4}$

${ }^{1}$ Section of Conservation Biology, University of Basel, Basel, Switzerland

${ }^{2}$ Balaton Limnological Institute, Centre for Ecological Research, Hungarian Academy of Sciences, Tihany, Hungary

${ }^{3}$ Ecosystem Change Unit, Finnish Environment Institute, Oulu, Finland ${ }^{4}$ Department of Biology, University of Oulu, Oulu, Finland

*Correspondence: Dénes Schmera, Section of Conservation Biology, University of Basel, St. Johanns-Vorstadt 10, CH-4056 Basel, Switzerland, email: denes.schmera@unibas.ch, Tel.: +4161 2670856, Fax: +41612670832 
Keywords: diversity, headwater streams, natural environmental variation, stream macroinvertebrates, trait-based analyses.

Abstract: Although our knowledge of the spatial distribution of stream organisms has been increasing rapidly in the last decades, there is still little consensus about traitbased variability of macroinvertebrate communities within and between catchments in near-pristine systems. Our aim was to examine the taxonomic and trait based stability vs. variability of stream macroinvertebrates in three high-latitude catchments in Finland. The collected taxa were assigned to unique trait combinations (UTCs) using biological traits. We found that only a single or a highly limited number of taxa formed a single UTC, suggesting a low degree of redundancy. Our analyses revealed significant differences in the environmental conditions of the streams among the three catchments. Linear models, rarefaction curves and beta-diversity measures showed that the catchments differed in both alpha and beta diversity. Taxon- and trait-based multivariate analyses also indicated that the three catchments were significantly different in terms of macroinvertebrate communities. All these findings suggest that habitat filtering, i.e., environmental differences among catchments, determines the variability of macroinvertebrate communities, thereby contributing to the significant biological differences among the catchments. The main implications of our study is that the sensitivity of trait-based analyses to natural environmental variation should be carefully incorporated in the assessment of environmental degradation, and that further studies are needed for a deeper understanding of trait-based community patterns across near-pristine streams. 
Nomenclature: Fauna Europaea (2012).

Abbreviations: AIC-Akaike's Information Criterion; ANOVA-Analysis of Variance; BC-Bray-Curtis dissimilarity; CAP-Constrained Analysis of Principal Coordinates; EU-Euclidean distance; LM-Linear model; MRPP-Multiple Response Permutation Procedure; PCA-Principal Component Analysis; PERMDISP-Test of Homogeneity of Dispersion; SIM-Simpson dissimilarity; SOR-Sørensen dissimilarity; UTC-Unique Trait Combination. 


\section{Introduction}

Understanding how biotic communities are organized is one of the main goals of community ecology (Gotelli and Graves 1996). Ecologists have long stressed that community organization reflects multiple biotic and abiotic factors, the relative importance of which often varies with ecosystem type (Begon et al. 2006). In stream ecosystems, the abiotic environment is regarded as a major structuring force for biotic communities (Allan and Castillo 2007, Giller and Malmqvist 1998), and this idea is also at the core of the theory of habitat templets (Southwood 1977). This theory predicts that the properties of stream habitat determine the composition and diversity of biotic communities (Townsend and Hildrew 1994, Statzner et al. 2001a) and suggests that the habitat filters organisms through their biological traits to coexist at a locality (Townsend and Hildrew 1994, Poff 1997, Statzner et al. 2001a). Trait-based community analyses are comparable among all types of organisms, and they may reveal unified and easily-interpretable patterns even across biogeographically distinct regions that differ in the taxonomic composition of their species pools. Due to these features, trait-based community analyses are now routinely applied in stream ecology (Doledec and Statzner 2008, Statzner and Beche 2010).

Near-pristine streams are extremely heterogeneous ecosystems with high spatial and temporal variability (Townsend 1989, Ward et al. 2000, Beche and Resh 2006). A number of studies have suggested that stream macroinvertebrates respond to the type and arrangement of habitat patches and show, therefore, pronounced spatial and temporal heterogeneity (Hart and Finelli 1999, Palmer et al. 2000, Townsend et al. 2003). As a consequence, for example, several studies have found variable correspondence between landscape classifications and the taxonomic composition of 
stream macroinvertebrate communities (Hawkins and Vinson 2000, Heino et al. 2002). Furthermore, Poff et al. (2010) recently pointed out that we still lack adequate knowledge of trait variation across extensive environmental gradients: "However, whether traits-based reference conditions are stable across strong environmental gradients (e.g. ecoregions) within major climatic zones has not yet been adequately examined" (p. 1443 in Poff et al. 2010).

Studying the stability or variation of community traits in near-pristine streams is relevant to both pure and applied ecology. First, the theoretical model proposed by Poff (1997) stresses variation, because it predicts "the probability that individual species with specified functional attributes (species traits) are able to persist as members of a local community" (p. 392 in Poff 1997). Moreover, a recent study showed that reach-level factors explained $45 \%$ variation in community traits (including the interactions with other factors) in constrained ordination, a value that is comparable to climate (56\%) and non-climate (42\%) related factors (Poff et al. 2010). Although trait-based community analyses are now routinely applied in stream ecology (Doledec and Statzner 2008, Statzner and Beche 2010), we did not find any research focusing on how trait variability within catchments is related to among-catchment variation. Such an analysis would add to testing the predictions of the hierarchical filtering model of Poff (1997) and supplement our knowledge on how the variation of the community traits of stream macroinvertebrates reflects the hierarchy of natural stream ecosystems.

Regarding assessment issues, the incorporation of natural variation of community traits in bioassessment protocols is gaining increasing interest. However, despite theoretical predictions (e.g. Poff 1997) and empirical evidence (e.g. Poff et al. 2010) on the existence of natural variation in community traits, some authors 
suggested a high stability (i.e. very little variation) in community traits of stream macroinvertebrates in natural regions scattered across Europe (Statzner et al. 2001b). Consequently, there is still no consensus on the natural variability of traits among catchments within and between regions and if and how bioassessment should incorporate natural variation of community traits into practical procedures.

Motivated by either theoretical or practical considerations, several biodiversity studies have examined the degree of match between taxonomy-based and trait-based community analyses. Some studies have shown agreement between these two types of community analyses, whereas others indicated mismatches both in the terrestrial and aquatic realms (Heino et al. 2007, Hoeinghaus et al. 2007, Devictor et al. 2010). Although these sometimes contradictory findings have contributed to our understanding of how biotic communities are organized in running waters, they have also distracted attention from how trait-based community assessment reflects natural variation of streams. Therefore, the relationships between community traits and environmental variation across near-pristine streams and among regions should be examined rigorously.

In this study, we examined variation in the environmental variables and the trait diversity of macroinvertebrate communities of near-pristine headwater streams in three catchments at high latitudes. Our primary aim was to test whether natural variation allows the separation of catchments using community traits. Following Poff's (1997) ideas, our hypothesis was that if the catchments differ in natural stream environmental conditions, also macroinvertebrate community traits should show consequent differences among catchments.

\section{Methods}




\section{Study areas}

The southernmost of the study areas is located in the lijoki drainage basin (centered on $65^{\circ} \mathrm{N}, 27^{\circ} \mathrm{E}$ ). The study area is characterized by middle boreal coniferous forests and peatlands. Headwater streams in the drainage basin are often modified by forestry, drainage and log floating, although some near-pristine running waters are also present. These streams are under no or low human-impact pressures. We sampled only such near-pristine sites, based on information obtained from regional environmental authorities. We surveyed 20, first to third order, streams in the Iijoki drainage basin (Fig. 1b). The total area of the Iijoki drainage basin is $14191 \mathrm{~km}^{2}$.

The easternmost of the study areas is located in the Koutajoki drainage basin in northeastern Finland (centered on $66^{\circ} \mathrm{N}, 29^{\circ} \mathrm{E}$ ). The bedrock of the study area is highly variable, with extensive occurrences of calcareous rocks. Accompanied by considerable altitudinal difference, this geological variability is mirrored in highly variable vegetation, ranging from northern boreal coniferous forests to mixeddeciduous riparian woodlands, and from nutrient-poor bogs to fertile fens. These factors also provide the basis for a high variability of stream habitats across the drainage basin (Heino et al. 2009). Headwater streams in the drainage basin are generally near-pristine, and they are characterized by circumneutral to alkaline water, low to high levels of humic substances, and low to moderate nutrient concentrations. A detailed description of the study area can be found elsewhere (Malmqvist et al. 2009). We surveyed 20, first to third order, streams selected from those available in the Finnish part of the Koutajoki drainage basin (Fig. 1c). The total area of the Koutajoki drainage basin is ca. $24500 \mathrm{~km}^{2}$. 
The northernmost of the study areas is located in the Tenojoki drainage basin (centered on $70^{\circ} \mathrm{N}, 27^{\circ} \mathrm{E}$ ). This subarctic study area is characterized by arctic-alpine vegetation, comprising mountain birch woodlands at low altitude and barren fell tundra at higher altitude. Stream waters are circumneutral, and nutrient levels are indicative of ultraoligotrophic systems (Heino et al. 2003). Headwater streams in the drainage basin range from pristine to near-pristine, as forestry and associated land uses are not generally feasible at these latitudes. We surveyed 30, first to fourth order, headwater tributary streams in the Tenojoki drainage basin, draining into the main stem of the River Tenojoki (Fig. 1a). The total area of the Tenojoki drainage basin is $16386 \mathrm{~km}^{2}$.

\section{Environmental variables}

We measured several riparian, in-stream habitat and water chemistry variables at each site (the following is based on methods in Heino et al. 2012). Percentage cover of deciduous trees was assessed in a 50-m section on both banks directly upstream of the sampling site. Shading was estimated visually as percent canopy cover at 20 locations along transects (the number of which depended on stream width) at the whole study section. Current velocity (at $0.6 \times$ depth) and depth were measured at 30 random locations along cross-stream transects, the number of which depended on stream width. Stream wetted width was measured at each site based on five crossstream transects. Moss cover (\%) and substratum particle class cover (\%) were assessed at ten random randomly spaced $50 \mathrm{~cm} \times 50 \mathrm{~cm}$ quadrates. Visual estimates of the percentage cover of five particle size classes were made for each quadrate using a modified Wentworth scale: (i) sand (diameter $0.25 \mathrm{~mm}-2 \mathrm{~mm}$ ), (ii) gravel (2 mm $16 \mathrm{~mm}$ ), (iii) pebble (16 mm - $64 \mathrm{~mm})$, (iv) cobble (64 mm - $256 \mathrm{~mm})$, (v) boulder 
(256 mm - $1024 \mathrm{~mm})$. Water samples were collected simultaneously with the field sampling, and they were analyzed for $\mathrm{pH}$, conductivity, water color, and total phosphorus using Finnish national standards (National Board of Water and the Environment 1981). Water color and total phosphorus were not determined in the Tenojoki drainage basin, as there is little variability in color, and total phosphorus is typically below easily detectable limits $(<5 \mu \mathrm{g} / \mathrm{l})$.

\section{Macroinvertebrate data}

Stream macroinvertebrates were sampled in the Koutajoki catchment in the last week of May in 2008, in the Iijoki catchment in the last week of May in 2009, and in the Tenojoki catchment in the second week of June 2010. This is the season when the majority of macroinvertebrates in high latitude streams are still in the larval stage. This was evidenced during the field sampling by the fact that we observed only occasional adult stoneflies flying around the streams (Heino et al. 2009). The timing of sampling also facilitated the identification of aquatic insect larvae, most of which are close to their maximum size at this time of the year. Although the streams were sampled in different years, we considered it more important to sample the streams in the exactly same season (i.e. immediately after the snow-melt) than sample the streams during a longer time period in the same year. This decision was made because temporal changes in community composition in early summer are fast in northern headwater streams, and sampling all the sites within a short period in a single year would not have been logistically possible.

At each site, we took a two-minute kick-net (net mesh size $0.3 \mathrm{~mm}$ ) sample covering most microhabitats present in a riffle of approximately $100 \mathrm{~m}^{2}$. This sampling effort typically yields more than $70 \%$ of species occurring at a headwater 
site in a given season, mainly missing rare tourist species that occur only sporadically in headwater streams (Mykrä et al. 2006). Macroinvertebrates and associated material were immediately preserved in $70 \%$ ethanol in the field, and the samples were taken to the laboratory for further processing and identification. All macroinvertebrates were sorted and identified to the lowest feasible level following the nomenclature of Fauna Europaea (2012). However, due to missing trait information, we did not include the dipterans in this study.

We started the analyses with 20424 individuals and they were assigned to 112 taxa. The taxa were characterized by 11 biological traits (with 64 modalities, see Table 1) following Tachet et al. (2000). This trait database summarized expert knowledge about freshwater invertebrate taxa by assigning an affinity score of each taxon to each modality using a fuzzy coded approach (Chevenet et al. 1994). However, we had to reduce our taxa list (consequently the number of individuals: in the Tenojoki catchment by 84 individuals, in the Iijoki catchment by 8 individuals, and in the Koutajoki catchment by 52 individuals), because the trait data set was incomplete for many taxa (e.g. some species of Oligochaeta and Arachnida). After this reduction, each taxon could be fully characterized by the biological traits listed in Table 1. Using the mentioned biological traits (Table 1), taxa were assigned to unique trait combinations (UTCs, see Erős et al. 2009). By definition, an UTC contains taxa with identical values for each modality category of biological traits and the term UTC is equivalent with the term functional unit (Schmera et al. 2009a, 2009b) and the term functional species (Ricotta 2005).

\section{Statistical analyses}


Analysis of Variance (ANOVA) and Kruskal-Wallis test were performed to test for significant among-region differences in each environmental variable.

Constrained Analysis of Principal Coordinates (CAP, Anderson and Willis 2003) with Euclidean distance (EU, Podani 2000) was used to test the separation of the regions using standardized environmental variables (all values were divided by the maximum of the variable found in the sample).

$$
E U=\left[\sum_{i=1}^{n}\left(x_{i j}-x_{i k}\right)^{2}\right]^{1 / 2},
$$

where $x_{i j}$ and $x_{i k}$ are the value of environmental variable $i$ at site $j$ and $k$, respectively. The number of environmental variables equals to $n$. CAP is simply a Redundancy Analysis of results of Metric Multidimensional Scaling (Anderson and Willis 2003). We ran an ANOVA-like permutation to test for the significance of the separation of regions in multivariate space. In this test, the number of permutations is controlled by targeted "critical" P value (alpha) and accepted Type II or rejection error (beta). If the results of permutations differ from the targeted alpha at the risk level given by beta, the permutations were terminated (Oksanen et al. 2010). Our ANOVA-like permutation tests were terminated at 199 permutations. Correlation-based vectors of taxa and UTCs were fitted onto the environmental variables-based ordination (envfit function of the vegan package, Oksanen et al. 2010) to see which taxa or UTCs were related to the separation of catchments. We tested them with a randomization test (10000 runs).

Linear models (LMs) with regions as categorical predictors were used to compare the numbers of taxa, UTCs and individuals among regions. Individual-based rarefaction curves (Hurlbert 1970) and their standard error (Heck et al. 1975) were drawn to compare taxon richness or number of UTCs of the regions independently 
from the number of individuals collected (i.e. samples within the region were pooled). Sample-based rarefaction curves (called also as species accumulation curve) were drawn to compare taxon richness or number of UTCs of the regions independently of the number of sites sampled.

Beta diversity of macroinvertebrates within each region was expressed by the test of homogeneity of dispersion (PERMDISP) developed by Anderson (2006) and Anderson et al. (2006). PERMDISP quantifies the multivariate homogeneity of group dispersions (variance) and is a multivariate analogue of Levene's test for homogeneity of variances. PERMDISP was calculated separately based on taxa and UTCs using both presence/absence and abundance data. We used the Sørensen dissimilarity (SOR) for presence/absence data and Bray-Curtis dissimilarity (BC) for abundance data to quantify beta diversity.

$$
S O R=\frac{b+c}{2 \mathrm{a}+b+c} \text { and } B C=\frac{\sum_{i=1}^{T}\left|x_{i j}-x_{i k}\right|}{\sum_{i=1}^{T}\left(x_{i j}+x_{i k}\right)}
$$

where $a$ is the number of taxa/UTCs present at both sites, whereas $b$ and $c$ are the numbers of taxa/UTCs present only at the first and only at the second sites, respectively. For BC dissimilarity, $x_{i j}$ and $x_{i k}$ are the abundance of taxa/UTCs $i$ at site $j$ and $k$, respectively. The number of taxa/UTCs equals to $T$. To test whether the observed pattern of presence/absence-based beta diversity (Sørensen dissimilarity) was caused by species replacement and not by richness difference (see terms in Podani and Schmera 2011, Schmera and Podani 2011), we re-ran our analyses with Simpson dissimilarity (SIM, see Simpson 1943, Lennon et al. 2001), because Simpson dissimilarity is insensitive to richness difference (Koleff et al. 2003).

$$
S I M=\frac{\min (b, c)}{a+\min (b, c)}
$$


where $a$ is the number of taxa/UTCs present at both sites, whereas $b$ and $c$ are the numbers of taxa/UTCs present only at the first and only at the second sites, respectively. We used permutation to test differences in beta diversity among regions and for making pairwise comparisons (the number of permutations was 999).

CAP was also run to test for the separation of regions based on macroinvertebrate communities using both taxa and UTCs. Multiple Response Permutation Procedure (MRPP, McCune and Grace 2002) was used to test how the separation of catchment (among-catchment dissimilarity) is related to the withincatchment stability (within-catchment dissimilarity) using both taxa and UTCs. In both cases, we ran separate analyses for presence/absence data using Sørensen (SOR) or Simpson (SIM) dissimilarities and for abundance data using Bray-Curtis dissimilarity $(\mathrm{BC})$.

Linear models with environmental variables as continuous predictors were used to test if environmental variables were related to variation in the taxon richness and the number of UTCs. For linear models, we always started with a full main-effect model and minimal adequate model was selected based on Akaike's Information Criterion (AIC). We provide the ANOVA output of the minimal adequate models.

The calculation of dissimilarity matrices, CAP analyses, permutation tests in CAP, PERMDISP, MRPP, PCA and rarefaction curves were performed with the vegan package (Oksanen et al. 2010) in the R statistical environment (R Development Core Team 2009).

\section{Results}


Each environmental variable varied significantly among the catchments (Table 2). In agreement with the analyses for individual environmental variables, CAP showed overall differences between the study catchments regarding the environmental variables measured at the sampling sites (Fig. 2, ANOVA-like permutation $F=$ $20.859, p=0.005)$.

Our analyzed data set contained 20280 macroinvertebrate individuals assigned to 99 taxa (Electronic Appendix 1). The combination of 11 traits (with 64 modalities) and 99 taxa resulted in 65 UTCs. Most UTCs contained a single taxon, whereas some UTCs included 2, 3 or 4 taxa (Fig. 3). We found the highest total taxon richness (gamma diversity) in the Koutajoki catchment (74 taxa), followed by the Iijoki (58) and the Tenojoki (34) catchments.

LMs showed that the streams in the three catchments differed in the numbers of taxa (ANOVA $\left.F_{2,67}=30.375, p<0.001\right)$, UTCs (ANOVA $F_{2,67}=39.618, p<0.001$ ) and individuals (ANOVA $F_{2,67}=3.561, p<0.034$ ). Koutajoki and Iijoki supported higher numbers of taxa and UTCs than Tenojoki, and Iijoki had the highest number of individuals (Fig. 4). Sample-based and individuals-based rarefaction curves showed that the catchments differ in the expected taxon richness and expected number UTCs. Koutajoki had the highest expected taxon richness and number of UTCs, followed by Iijoki and Tenojoki (Fig. 5).

PERMDISP analyses showed that beta diversity differs significantly between the catchments when presence/absence of the taxa (Sørensen dissimilarity, $F=4.521$, $p=0.014$, Fig. 6A; Simpson dissimilarity, $F=13.921, p=0.001$, Fig. 6B), abundance of the taxa (Bray-Curtis dissimilarity, $F=5.674, p=0.007$, Fig. $6 \mathrm{C}$ ) and presence/absence of the UTCs were considered (Sørensen dissimilarity, $F=4.316, p=$ 0.0013, Fig. 5D; Simpson dissimilarity, $F=10.448, p=0.001$, Fig. 6E). In contrast, 
beta diversity did not differ between the catchments when abundances of the UTCs were considered (Bray-Curtis dissimilarity, $F=2.552, p=0.085$, Fig. 6F). Pairwise comparisons of beta diversity values showed that Koutajoki had higher beta diversity than the other two catchments (Fig. 6).

CAP showed that the three catchments differed in taxa composition (presence/absence of taxa analyzed by Sørensen dissimilarity, $F=16.123, p=0.005$, Fig. 7A; presence/absence of taxa analyzed by Simpson dissimilarity, $F=13.967, p=$ 0.005, Fig. 7B), in taxa abundance (abundance of taxa analyzed by Bray-Curtis dissimilarity, $F=8.654, p=0.005$, Fig. $7 \mathrm{C}$ ), in the composition of UTCs (presence/absence of UTCs analyzed by Sørensen dissimilarity, $F=9.657, p=0.005$, Fig. 7D; presence/absence of UTCs analyzed by Simpson dissimilarity, $F=9.658, p=$ 0.005, Fig 7E) and in the abundance of UTCs (abundance of UTCs analyzed by BrayCurtis dissimilarity, $F=4.436, p=0.005$, Fig. $7 F$ ).

MRPP showed that the separation of catchments is significantly higher than within-catchment stability using taxon composition (presence/absence of taxa analyzed by Sørensen dissimilarity, $A$-value $=0.219, p=0.001$, presence/absence of taxa analyzed by Simpson dissimilarity, $A$-value $=0.295, p=0.001)$, taxa abundance (abundance of taxa analyzed by Bray-Curtis dissimilarity, $A$-value $=0.114, p=0.001$ ), trait composition (presence/absence of UTCs analyzed by Sørensen dissimilarity, Avalue $=0.154, p=0.001$, presence/absence of UTCs analyzed by Simpson dissimilarity, $A$-value $=0.124, p=0.001$ ) and in the abundance of UTCs (abundance of traits analyzed by Bray-Curtis dissimilarity, $A$-value $=0.060, p=0.001)$.

The fit of the vectors of taxa showed that Heptagenia dalecarlia (Ephemeroptera), Leuctra hippopus (Plecoptera) and Nemoura sp. (Plecoptera) differed among the Tenojoki catchment from the Koutajoki and Iijoki catchments, 
whereas several taxa differed among the other two catchments (not shown). Traitbased analysis did not find any UTC that would separate the Tenojoki catchment, whereas several other UTCs differed among the other two catchments (Fig 2).

Linear models were used to test how well environmental variables accounted for variation in taxa richness and the number of UTCs. As variables reflecting instream substrate composition (i.e. the percentage of sand, gravel, pebble, cobble and boulder) are not independent, we transformed them into two independent variables using Principal Component Analysis (PCA, Podani 2000). The first two axes of the PCA explained $85.4 \%$ of the substrate variability among sampling sites, thus we used the first axis values of the sites as a variable "substrate 1", whereas the second axis values as "substrate 2 " in the further analyses. The minimal adequate models showed that environmental variables $\mathrm{pH}$, water depth and riparian deciduous vegetation have a significant impact on taxon richness, whereas $\mathrm{pH}$, conductivity and riparian deciduous vegetation were related to the number of UTCs (Table 3). Environmental variables explained slightly more variation in the number of UTCs than in taxon richness (Table 3).

\section{Discussion}

Although trait-based community analyses are routinely applied in biodiversity studies, their sensitivity to natural environmental variation in space and time has been rarely examined. Here, we tested if abiotic environmental differences among catchments affect the trait composition and diversity of macroinvertebrate communities in near-pristine streams at high latitudes. Our results showed that the 
catchments we examined show (i) considerable divergence in the underlying habitat template, (ii) high variability in macroinvertebrate diversity and community structure, and (iii) differences in the taxonomy-based and trait-based composition and diversity of stream macroinvertebrates. These findings emphasize that natural variability of macroinvertebrate community traits does exist, and that it is structured by the habitat template.

In their pioneering study, Statzner et al. (2001b) predicted that near-pristine streams in different regions across Europe have similar environmental conditions. In the present study, we focused only on high-latitude streams and provided strong statistical evidence that the environmental conditions of near-pristine headwater streams in different catchments are highly different. Our findings were in agreement with previous studies emphasizing regional differences in environmental variables of streams (Ward et al. 2000, Heino et al. 2002) and provided a chance to test whether or not the traits of stream macroinvertebrates are sensitive to natural environmental variation among and within catchments.

The diversity and composition of biotic communities reflect the spatial and temporal variability of stream habitats (Palmer et al. 2000, Townsend et al. 2003). It follows that the taxonomic richness of macroinvertebrates in headwater streams is highly variable (Li et al. 2001, Boyero 2003) and shows distinct differences among continents and regions (Hawkins and Vinson 2000, Clarke et al. 2008). Our results are in agreement with these observations, because we found that the taxonomic composition and diversity of high-latitude streams in catchments under different abiotic environmental conditions show considerable differences. We also provided statistical evidence that, in contrast to a remarkable variability, catchments under different natural abiotic environmental conditions show differences in community 
traits. This finding is in agreement with a limited number of studies that have already reported significant differences in trait composition of macroinvertebrates across different natural habitat types (Statzner et al. 1994, Statzner and Beche 2010) or with the response of traits to stressor gradients (Pollard and Yuan 2010). Our results, in contrast, disagree with the prediction that the trait-based composition of macroinvertebrates shows extremely high stability across natural headwater streams (Statzner et al. 2001b).

Studies examining the congruence between taxonomy-based and trait-based analyses show contradictory results (Heino et al. 2007, Hoeinghaus et al. 2007, Doledec et al. 2011). When comparing the diversity and composition of macroinvertebrate communities in the three catchments, we ended up with similar conclusions based on both the taxonomy-based and trait-based analyses. Moreover, this congruence received additional support by the linear models: $\mathrm{pH}$ and riparian deciduous vegetation explained relatively well variation in both taxon richness and the number of UTCs. A possible explanation for this congruence might be that only a single or a highly limited number of taxa form a single UTC, similarly to that found in the fish assemblages of boreal lakes (Erős et al. 2009), although the situation is not so clear for stream macroinvertebrates than for lake fish. We should also note that highlatitude streams do not support highly diversified biotas, because no specialization is likely to have evolved there. Rather, high-latitude biotas have formed by colonization from the south following the retreat of ice following the end of the latest ice age (e.g., Heino 2001). All these factors may contribute to macroinvertebrate communities with only a few confamilial or congeneric species being present at each locality and in the catchment-level species pools (e.g., Heino 2005). Note that we observed the lowest number of taxa and UTCs in our northernmost study catchment, and the separation of 
this catchment from the other two was related to only three taxa but no UTCs. In sum, these findings suggest that high latitude streams provide harsh environmental conditions for organisms, and only a single or a limited number of taxa potentially occupy similar niches (as expressed by the UTCs). From a technical point of view, it would be possible to reduce the number of traits (and modalities) in our trait database in order to increase the redundancy in our system. However, we did not do this to make our result comparable to other studies using the same European trait-database.

Our study catchments showed distinct differences in the stream environmental variables. These findings suggest that environmental differences among catchments are responsible for the regional differences in the diversity and composition of stream macroinvertebrate communities. Consequently, natural environmental differences among catchments generate among-catchment variation in the trait-based diversity and community patterns of stream macroinvertebrates. This result is, in fact, in agreement with the findings of Statzner et al. (1994), who found that natural habitat types of the Upper Rhone River show statistically different trait composition patterns. In our study system, $\mathrm{pH}$ is one of the environmental factors that separate the Koutajoki catchment from the other two catchments (Table 2). If water $\mathrm{pH}$ decreased in this catchment, such a process would likely remove acid-sensitive taxa and UTCs. If such an acidification process occurred in the future, then the Koutajoki catchment would no longer be separated from the other two basins in terms of taxa and UTCs.

The among-catchment variation in the trait composition of stream macroinvertebrate communities suggests that biodiversity patterns based on species traits are not necessarily as stable as it was suggested earlier (Statzner et al. 2001b). The sensitivity of trait-based analyses to natural variation should be regarded as a hint for applied ecologists: significant variation in trait composition can not necessarily be 
regarded as a signal of human impact only. Moreover, our information is rather limited on if or how human impact changes such biological variation. Therefore, we strongly recommend the examination of how species traits in ecological communities vary in response to environmental gradients within other geographical regions (or is the pattern we observed just a specific feature of high-latitude streams?) and the assessment of trait variability for quantifying threshold levels for detecting human impact (or how the human impacts are related to natural variability?). This hint, in fact, encourages researchers to incorporate natural environmental variation in the context of trait-based environmental assessment in a more straightforward way.

Near-pristine headwater streams provide habitat for biological communities with remarkable variability. Our comparison of stream macroinvertebrate communities in catchments under different abiotic environmental conditions showed high variability, but also pointed out that catchments also differed significantly in community composition. All these findings suggest that habitat filtering, i.e., the environmental differences among catchments, determines biological variability and contributes to the separation of the catchments based on macroinvertebrate communities. The implication of our study is that the sensitivity of trait-based analyses to natural variation should carefully be incorporated in bioassessment to sharpen our ability to detect human impacts. Finally, we encourage ecologists to utilize trait-based community analyses for answering multiple interesting questions, while considering the natural variability of stream ecosystems.

\section{Acknowledgements}


This study was supported by grants from the Academy of Finland, Maj and Tor Nessling Foundation and Kone Foundation. Tibor Erős was additionally supported by the János Bolyai Research Scholarship of the Hungarian Academy of Sciences and the OTKA K 104279 research fund. We thank Mira Grönroos, Tommi Karhu and Heikki Mykrä for help with the field work. We are indebted to Jari Ilmonen, Tommi Karhu and Lauri Paasivirta for identifying the macroinvertebrate material.

\section{References}

Allan, J.D. and M. M. Castillo. 2007. Stream ecology. Structure and function of running waters. Second edition. Springer, Dordrecht

Anderson, M. J. 2006. Distance-based tests for homogeneity of multivariate dispersions. Biometrics 62:245-253.

Anderson, M. J., K. E. Ellingsen and B. H. McArdle. 2006. Multivariate dispersion as a measure of beta diversity. Ecol. Let. 9:683-693.

Anderson, M. J. and T. J. Willis. 2003. Canonical analysis of principal coordinates: a useful method of constrained ordination for ecology. Ecology 84:511-525.

Beche, L. A. and V. H. Resh. 2006. Long-term seasonal variation in the biological traits of benthic-macroinvertebrates in two Mediterranean-climate streams in California, U.S.A.. Freshw. Biol. 51:56-75.

Begon, M., C. R. Townsend and J. L. Harper. 2006. Ecology. From Individuals to Ecosystems. Blackwell Publishing Ltd 
Boyero, L. 2003. Multiscale patterns of spatial variation in stream macroinvertebrate communities. Ecol. Res. 18:365-379.

Chevenet F., S. Doledec, D. Chessel. 1994. A fuzzy coding approach for analysis of long-term ecological data. Freshw. Biol. 31:295-309.

Clarke, A., R. Mac Nally, N. Bond and P. S. Lake. 2008. Macroinvertebrate diversity in headwater streams: a review. Freshw. Biol. 53:1707-1721.

Devictor, V., D. Mouillot, C. Meynard, F. Jiguet, W. Thuiller and N Mouquet. 2010. Spatial mismatch and congruence between taxonomic, phylogenetic and functional diversity: the need for integrative conservation strategies in a changing world. Ecol. Let. 13:1030-1040.

Doledec, S. and B. Stazner. 2008. Invertebrate traits for the biomonitoring of large European rivers: an assessment of specific types of human impact. Freshw. Biol. 53:617-634.

Erös, T. 2007. Partitioning the diversity of riverine fish: the roles of habitat types and non-native species. Freshw. Biol. 52:1400-1415.

Erős, T., J. Heino, D. Schmera and M. Rask. 2009. Characterising functional trait diversity and trait-environment relationships in fish assemblages of boreal lakes. Freshw. Biol. 54:1788-1803.

Fauna Europaea (2012) Fauna Europaea version 2.5. Web Service available online at http://www.faunaeur.org

Giller, P.S. and B. Malmqvist. 1998. The biology of streams and rivers. Oxford University Press, Oxford

Gotelli, N. J. and G. R. Graves. 1996. Null models in ecology. Smithsonian Institution Press, Washington, DC 
Hart, D. D. and C. M. Finelli. 1999. Physical-biological coupling in streams: the pervasive effects of flow and benthic organisms. Ann. Rev. Ecol. Syst. 30:363395.

Hawkins, C. P. and M. R. Vinson. 2000. Weak correspondence between landscape classifications and stream invertebrate assemblages: implications for bioassessment. J. North. Am. Benthol. Soc. 19:501-517.

Heck, K. L., G. van Belle and D. Simberloff. 1975. Explicit calculation of the rarefaction diversity measurement and the determination of sufficient sample size. Ecology 56:1459-1461.

Heino. J, 2001. Regional gradient analysis of freshwater biota: do similar biogeographic patterns exist among multiple taxonomic groups? J. Biogeog. 28:69-77.

Heino, J. 2005. Positive relationship between regional distribution and local abundance in stream insects: a consequence of niche breadth or niche position? Ecography 28:345-354.

Heino, J., M. Grönroos, J. Soininen, R. Virtanen and T. Muotka. 2012. Context dependency and metacommunity structuring in boreal headwater streams. Oikos 121:537-544.

Heino, J., J. Ilmonen, J. Kotanen, H. Mykrä, L. Paasivirta, J. Soininen and R. Virtanen. 2009. Surveying biodiversity in protected and managed areas: algae, macrophytes and macroinvertebrates in boreal forest streams. Ecol. Ind. 9:11791187.

Heino, J., T. Muotka and R. Paavola. 2003. Determinants of macroinvertebrate diversity in headwater streams: regional and local influences. J. Anim. Ecol. 72:425-434. 
Heino, J., T. Muotka, R Paavola, H. Hamalainen and E. Koskenniemi. 2002. Correspondence between regional delineations and spatial patterns in macroinvertebrate assemblages in boreal headwater streams. J. North Am. Benth. Soc. 21:397-413.

Heino, J., H. Mykrä, J. Kotanen and T. Muotka. 2007. Ecological filters and variability in stream macroinvertebrate communities: do taxonomic and functional structure follow the same patch? Ecography 30:217-230.

Hoeinghaus, D. J., K. O. Winemiller and J. S. Birnbaum. 2007. Local and regional determinants of stream fish assemblage structure: interference based on taxonomic vs. functional groups. J. Biogeog. 34:324-338.

Hurlbert, S. H. 1971. The nonconcept of species diversity: a critique and alternative parameters. Ecology 52:577-586.

Koleff, P., K. G. Gaston and J. J. Lennon. 2003. Measuring beta diversity for presence-absence data. J. Anim. Ecol. 72:367-382.

Lennon, J. J., P. Koleff, J. J. D. Greenwood and K. J. Gaston. 2001. The geographical structure of British bird distributions: diversity, spatial turnover and scale. $J$. Anim. Ecol. 70:966-979.

Li, J., A. Herlihy, W. Gerth, P. Kaufmann, S. Gregory, S. Urquhart and P. D. Larsen. 2001. Variability in stream macroinvertebrates at multiple spatial scales. Freshw. Biol. 46:87-97.

Malmqvist, B., C. Nilsson, T. Muotka, H. Timm. 2009. Rivers of the Fennoscandian Shield. In: Rivers of Europe (Eds Tockner, K., U. Uehlinger and C. T. Robinson), pp. 297-336. Academic Press.

McCune, M. and J. B. Grace. 2002. Analysis of ecological communities. MjM Softwarer Design, Glenden Beach, Oregon, USA 
Mykrä, H., T. Ruokonen and T. Muotka. 2006. The effect of sample duration on the efficiency of kick-sampling in two streams with contrasting substratum heterogeneity. Verh. Int. Ver. Theor. Ang. Limnol. 29:1351-1355.

National Board of Waters and the Environment. 1981. Vesihallinnon analyysimenetelmät. Publication of the National Board of Waters, Finland, 213:1-136.

Oksanen, J., F. G. Blanchet, R. Kindt, P. Legendre, R. B. O'Hara, G. P. Simpson, P. Solymos, M. H. H. Stevens and H. Wagner. 2010. vegan: Community Ecology Package. R package version 1.17-4. http://CRAN.R-project.org/package=vegan

Palmer, M. A., C. M. Swan, K. Nelson, P. Silver and R. Alvestad. 2000. Streambed landscapes: evidence that stream invertebrates respond to the type and spatial arrangement of patches. Landscape Ecol. 15:563-576.

Podani, J. 2000. Introduction into the exploration of multivariate biological data. Backhuys Publisher, Leiden, The Netherlands

Podani, J. and D. Schmera. 2011. A conceptual and methodological framework for exploring and explaining pattern in presence-absence data. Oikos 120:16261638.

Pollard, A. I. and L. L. Yuan. 2010. Assessing the consistency of response of metrics of the invertebrate benthos: a comparison of trait- and identity-based measures. Freshw. Biol. 55:1420-1429.

Ricotta, C. 2005. A note on functional diversity measures. Basic Appl. Ecol. 6:479486.

Poff, N. L. 1997. Landscape filters and species traits: towards mechanistic understanding and prediction in stream ecology. J. North Am. Benthol. Soc. 16:391-409. 
Poff NL, Pyne MI, Bledsoe BP, Cuhaciyan CC, Carlise DM (2010) Developing linkages between species traits and multiscaled environmental variation to explore vulnerability of stream benthic communities to climate change. J. North Am. Benthol. Soc. 29: 1441-1458.

R Development Core Team. 2009. $R$ : A language and environment for statistical computing. R Foundation for Statistical Computing, Vienna, Austria. ISBN 3900051-07-0, URL http://www.R-project.org.

Schmera, D., T. Erős and J. Podani. 2009a. A measure for assessing functional diversity in ecological communities. Aquat. Ecol. 43:157-176.

Schmera, D. and J. Podani. 2011. Comments on separating components of beta diversity. Com. Ecol. 12: 153-160.

Schmera, D., J. Podani and T. Erös. 2009b. Measuring the contribution of community members to functional diversity. Oikos 118:961-971.

Simpson, G. G. 1943. Mammals and the nature of continents. Am. J. Sci. 241:1-31.

Southwood, T. R. E. 1977. Habitat, the templet for ecological strategies? J. Anim. Ecol. 46:337-365.

Statzner, B. and A. L. Beche. 2010. Can biological invertebrate traits resolve effects of multiple stressors on running water ecosystems? Freshw. Biol. 55:80-119.

Statzner, B., B. Bis, S. Doledec and P. Usseglio-Polatera. 2001b. Perspectives for biomonitoring at large spatial scales: a uniform measure for the functional composition of invertebrate communities in European running waters. Bas. Appl. Ecol. 2:73-85.

Statzner, B., A. G. Hildew and V. H. Res. 2001a. Species traits and environmental constraints: entomological research and the history of ecological theory. Ann. Rev. Entomol. 46:291-316. 
Statzner, B., V. H. Resh and S. Doledec. 1994. Ecology of the Upper Rhone River: a test of habitat template theories. Freshw. Biol. 31:253-554.

Tachet, H., P. Richoux, M. Bournaud and P. Usseglio-Polatera. 2000. Invertébrés d'eau douce. Systematique, biologie, écologie. CNRS Editions, Paris

Townsend, C. R. 1989. The patch dynamics concept of stream community ecology. $J$. North Am. Benthol. Soc. 8:36-50.

Townsend, C. R., S. Doledec, R. Norris, K. Peadock and C. Arbuckle. 2003. The influence of scale and geography on relationships between stream community composition and landscape variables: description and prediction. Freshw. Biol. 48:768-785.

Townsend, C. R. and A. G. Hildrew. 1994. Species traits in relation to a habitat templet for river systems. Freshw. Biol. 31:265-275.

Usseglio-Polatera, P., M. Bournaud, M. Richoux and H. Tachet. 2000. Biological and ecological traits of benthic freshwater macroinvertebrates: relationships and definitions of groups with similar traits. Freshw. Biol. 43:175-205.

Ward, J. V., K. Tockner, D. B. Arscott and C. Claret. 2002. Riverine landscape diversity. Freshw. Biol. 47:517-539. 
Table 1: Traits and modalities (=categories) of aquatic macroinvertebrates used in this

study following Tachet et al. (2000) and Usseglio-Polatera et al. (2000).

\begin{tabular}{|c|c|}
\hline Traits & Modalities \\
\hline Maximal size & $\begin{array}{l}\leq 0.25 \mathrm{~cm} \\
0.25-0.5 \mathrm{~cm} \\
0.5-1 \mathrm{~cm} \\
1-2 \mathrm{~cm} \\
2-4 \mathrm{~cm} \\
4-8 \mathrm{~cm} \\
>8 \mathrm{~cm}\end{array}$ \\
\hline Life cycle duration & $\begin{array}{l}\leq 1 \text { year } \\
>1 \text { year }\end{array}$ \\
\hline Potential number of reproduction cycles per year & $\begin{array}{l}<1 \\
1 \\
>1\end{array}$ \\
\hline Aquatic stages & $\begin{array}{l}\text { egg } \\
\text { larva } \\
\text { pupa } \\
\text { adult }\end{array}$ \\
\hline Reproduction & $\begin{array}{l}\text { ovovivipary } \\
\text { isolated eggs, free } \\
\text { isolated eggs, cemented } \\
\text { clutches, cemented or fixed } \\
\text { clutches, free } \\
\text { eggs or clutches, in vegetation } \\
\text { (endophytic) } \\
\text { clutches, terrestrial } \\
\text { asexual reproduction } \\
\text { parthenogenesis }\end{array}$ \\
\hline Dispersal & $\begin{array}{l}\text { aquatic passive } \\
\text { aquatic active } \\
\text { aerial active } \\
\text { aerial passive }\end{array}$ \\
\hline Residence form & $\begin{array}{l}\text { eggs, statoblasts, gemmules } \\
\text { cocoons } \\
\text { cells against desiccation } \\
\text { diapause or dormancy } \\
\text { none }\end{array}$ \\
\hline Food & $\begin{array}{l}\text { fine sediment }+ \text { microorganisms } \\
\text { detritus }<1 \mathrm{~mm} \\
\text { plant detritus } \geq 1 \mathrm{~mm} \\
\text { living microhytes } \\
\text { living macrophytes } \\
\text { dead animals } \geq 1 \mathrm{~mm} \\
\text { living microinvertebrates } \\
\text { living macroinvertebrates } \\
\text { vertebrates }\end{array}$ \\
\hline Feeding habits & $\begin{array}{l}\text { absorber } \\
\text { deposit feeder } \\
\text { shredder } \\
\text { scraper } \\
\text { filter-feeder } \\
\text { piercer (plants or animals) } \\
\text { predator (carve/engulfer/swallower) } \\
\text { parasite, parasitoid }\end{array}$ \\
\hline Respiration & $\begin{array}{l}\text { tegument } \\
\text { gill } \\
\text { plastron } \\
\text { spiracle (aerial) } \\
\text { hydrostatic vesicle (aerial) }\end{array}$ \\
\hline Locomotion and substrate relation & $\begin{array}{l}\text { flier } \\
\text { surface swimmer } \\
\text { swimmer } \\
\text { crawler } \\
\text { burrower (epibenthic) } \\
\text { interstitial (endobenthic) } \\
\text { temporary attached } \\
\text { permanently attached }\end{array}$ \\
\hline
\end{tabular}


Table 2: Comparison of variation in the environmental variables between the three catchments. Variables are given as mean $( \pm \mathrm{SE})$ or as median (minimum - maximum) depending on the distribution of the data.

\begin{tabular}{|c|c|c|c|c|}
\hline \multicolumn{5}{|c|}{ Catchment } \\
\hline Environmental variable & Koutajoki & lijoki & Tenojoki & Comparison \\
\hline $\mathrm{pH}$ & $7.33( \pm 0.06)$ & $6.39( \pm 0.06)$ & $6.55( \pm 0.05)$ & ANOVA $F=70.69, P<0.001$ \\
\hline Conductivity (mS/m) & $6.98( \pm 0.66)$ & $2.09( \pm 0.66)$ & $1.83( \pm 0.56)$ & ANOVA $F=44.79, P<0.001$ \\
\hline Width $(m)^{1}$ & $2.99( \pm 0.82)$ & $3.04( \pm 0.82)$ & $5.75( \pm 0.67)$ & ANOVA $F=4.94, P=0.009$ \\
\hline Depth (cm) & $24.66( \pm 1.59)$ & $23.87( \pm 1.59)$ & $18.79( \pm 1.30)$ & ANOVA $F=5.13, P=0.008$ \\
\hline Velocity $(\mathrm{m} / \mathrm{s})^{2}$ & $0.51( \pm 0.03)$ & $0.40( \pm 0.03)$ & $0.36( \pm 0.02)$ & ANOVA $F=4.79, P=0.011$ \\
\hline Shading (\%) & $50(5-85)$ & $25(10-70)$ & $14(0-55)$ & Kruskal-Wallis $X^{2}=19.44, P<0.001$ \\
\hline Riparian deciduous vegetation (\%) & $40(10-75)$ & $35(5-80)$ & $100(98-100)$ & Kruskal-Wallis $\mathrm{X}^{2}=55.99, \mathrm{P}<0.001$ \\
\hline Macrophytes (\%) & $5.25(0-43)$ & $45.5(1-78)$ & $1.75(0-16)$ & Kruskal-Wallis $\mathrm{X}^{2}=32.66, \mathrm{P}<0.001$ \\
\hline Sand $(\%)$ & $4(0-73)$ & $6(0-49)$ & $0(0-22)$ & Kruskal-Wallis $\hat{x}^{2}=26.63, P<0.001$ \\
\hline Gravel (\%) & $7.5(0-30)$ & $2.5(0-37)$ & $0(0-25)$ & Kruskal-Wallis $\mathrm{X}^{2}=24.70, \mathrm{P}<0.001$ \\
\hline Pebble (\%) & $28(0-64)$ & $5(0-55)$ & $12(1-65)$ & Kruskal-Wallis $\mathrm{X}^{2}=20.24, \mathrm{P}<0.001$ \\
\hline Cobble (\%) & $26.5(0-51)$ & $32(0-53)$ & $45(9.5-81)$ & Kruskal-Wallis $\hat{X}^{2}=13.83, P<0.001$ \\
\hline Boulder (\%) & $12(0-92)$ & $48(0-82)$ & $33.25(0.5-83)$ & Kruskal-Wallis $\mathrm{X}^{2}=12.16, \mathrm{P}<0.001$ \\
\hline
\end{tabular}

test was performed on log transformed data

${ }^{2}$ test was performed on square-root transformed data 
Table 3: ANOVA table ( $d f$ : degrees of freedom, $S S$ : Sum of squares, $M S$ : Mean squares, $F$ : F-value, $p$ : probability, $\eta^{2}$ : effect size in $\%$ measured as the $S S_{\text {effect }} / S S_{\text {total }}$ ) of the minimal adequate models showing how environmental variables influence taxon richness and the number of unique trait combinations (UTCs). Significant effects are highlighted in bold.

\begin{tabular}{|c|c|c|c|c|c|c|c|}
\hline Response variable & Predictor & $d f$ & SS & MS & $F$ & $p$ & $\eta^{2}$ \\
\hline \multirow[t]{4}{*}{ Taxon richness } & $\mathrm{pH}$ & 1 & 508.20 & 508.20 & 24.871 & $<0.001$ & 17.46 \\
\hline & Water depth & 1 & 340.73 & 340.73 & 16.676 & $<0.001$ & 11.70 \\
\hline & Riparian deciduous veg. & 1 & 713.94 & 713.94 & 34.941 & $<0.001$ & 24.52 \\
\hline & Residuals & 66 & 1348.57 & 20.43 & & & 46.32 \\
\hline \multirow[t]{5}{*}{ Number of UTCs } & pH & 1 & 401.80 & 401.80 & 37.07 & $<0.001$ & 22.63 \\
\hline & Conductivity & 1 & 581.12 & 581.12 & 53.61 & $<0.001$ & 32.74 \\
\hline & Water depth & 1 & 38.72 & 38.72 & 3.57 & 0.063 & 2.18 \\
\hline & Riparian deciduous veg. & 1 & 49.07 & 49.07 & 4.527 & 0.037 & 2.76 \\
\hline & Residuals & 65 & 704.55 & 10.84 & & & 39.69 \\
\hline
\end{tabular}




\section{FIGURE LEGENDS}

Fig. 1. Maps of the study catchments: A) Tenojoki, B) Iijoki and C) Koutajoki. Study sites are shown by dots. Note that, in the Tenojoki catchment, the sampled headwater tributary sites were located near to but not in the main stem river.

Fig. 2. Ordination plot of the Constrained Analysis of Principal Coordinates (CAP) of the study sites based on environmental variables of the three catchments: Koutajoki (dark grey squares), Iijoki (light grey circles) and Tenojoki (white triangles). Axes loadings are given in percent of the total variability. Arrows show unique trait combinations significantly explaining variability.

Fig. 3. The number of unique trait combinations (Number of UTCs) in relation to the number of taxa per UTC (Number of taxa).

Fig. 4: Differences in the numbers of taxa, unique trait combinations and individuals among catchments. Columns show mean values, whiskers standard errors. Different letters denote significant differences based on the corresponding linear model.

Fig. 5. Sample-based (A, C) and individual-based (B, D) rarefaction curves show the expected taxon richness (A, B) and excepted number of UTCs (C, D) [solid line] $\pm \mathrm{SE}$ [dotted lines] in relation to the numbers of samples $(\mathrm{A}, \mathrm{C})$ and individuals $(\mathrm{B}, \mathrm{D})$ collected in the three catchments (Koutajoki, Iijoki and Tenojoki). 
Fig. 6: The results of PERMDISP analyses comparing the beta diversity (mean distance to centroid) of the three study catchments: Koutajoki (dark grey), Iijoki (light grey) and Tenojoki (white). A, B and C subfigures are based on taxa, whereas D, E and $\mathrm{F}$ are based on unique trait combinations (UTCs). A and D subfigures are based on presence-absence data using Sørensen dissimilarity index, B and E subfigures are based on presence-absence data using Simpson dissimilarity index, and $\mathrm{C}$ and $\mathrm{F}$ are based on abundance data using Bray-Curtis dissimilarity index. Different letters within a subfigure show significant differences in pairwise comparisons. In subfigure $\mathrm{F}$, pairwise comparison was not performed because overall test did not detect a significant difference in beta diversity between the regions.

Fig. 7: Results of Constrained Analysis of Principal Coordinates (CAP) showing the patterns of macroinvertebrate community structure in the three study catchments: Koutajoki (dark grey square), lijoki (light grey circle) and Tenojoki (white triangle). $\mathrm{A}, \mathrm{B}$ and $\mathrm{C}$ subfigures are based on taxa whereas $\mathrm{D}, \mathrm{E}$ and $\mathrm{F}$ are based on unique trait combinations. A and D subfigures are based on presence-absence data using Sørensen dissimilarity index, B and E subfigures are based on presence-absence data using Simpson dissimilarity index, and $\mathrm{C}$ and $\mathrm{F}$ subfigures are based on abundance data using Bray-Curtis dissimilarity index. 